\title{
Hepatitis B Virus Infection and the Kidney: Renal Abnormalities in HBV Patients, Antiviral Drugs Handling, and Specific Follow-Up
}

\author{
Gilbert Deray, ${ }^{1}$ Maria Buti, ${ }^{2}$ Ed Gane, ${ }^{3}$ Ji-Dong Jia, ${ }^{4}$ Henry Lik Yuen Chan, ${ }^{5}$ \\ Antonio Craxi, ${ }^{6}$ Teerha Piratvisuth, ${ }^{7}$ and Stanislas Pol ${ }^{8}$ \\ ${ }^{1}$ Paris 6 University, Nephrology Department, Pitie-Salpetriere University Hospital, Paris 75013, France \\ ${ }^{2}$ Liver Unit, Vall d'Hebron University Hospital, 08035 Barcelona, Spain \\ ${ }^{3}$ New Zealand Liver Transplant Unit, University of Auckland, Auckland 1010, New Zealand \\ ${ }^{4}$ Liver Research Center, Beijing Friendship Hospital, Capital Medical University, Beijing, China \\ ${ }^{5}$ Department of Medicine and Therapeutics, Institute of Digestive Disease and State Key Laboratory of Digestive Disease, \\ The Chinese University of Hong Kong, Hong Kong \\ ${ }^{6}$ Department of Internal Medicine and Medical Specialities (Di.Bi.M.I.S.), University of Palermo, 90133 Palermo, Italy \\ ${ }^{7}$ NKC Institute of Gastroenterology and Hepatology, Prince of Songkla University, Songklanagarind Hospital, Hat Yai, \\ Songkhla 90110, Thailand \\ ${ }^{8}$ Paris 5 University, Inserm U-1016, Hepatology Department, Cochin University Hospital, Paris 75005, France
}

Correspondence should be addressed to Gilbert Deray; gilbert.deray@psl.aphp.fr

Received 1 September 2014; Accepted 4 February 2015

Academic Editor: Jose J. Marin

Copyright (C) 2015 Gilbert Deray et al. This is an open access article distributed under the Creative Commons Attribution License, which permits unrestricted use, distribution, and reproduction in any medium, provided the original work is properly cited.

Chronic hepatitis $\mathrm{B}$ virus ( $\mathrm{CHB}$ ) infection is one of the most common causes of chronic liver disease, cirrhosis, and hepatocellular carcinoma (HCC) worldwide. Many patients with CHB have variable degrees of functional renal impairment, and approximately 2 to $15 \%$ of patients on hemodialysis have CHB. Several therapeutic regimens have been developed in the past years, among which oral nucleoside and nucleotide analogues have been demonstrated to be efficient and well tolerated. However, they all are excreted in the urine and may thus require dosage adjustment in patients with decreased renal function. Furthermore, a number of them may in addition be toxic to the kidneys, especially in those patients presenting with renal insufficiency.

\section{Introduction}

Chronic hepatitis $\mathrm{B}$ virus (CHB) infection is one of the most common causes of chronic liver disease, cirrhosis, and hepatocellular carcinoma (HCC) worldwide $[1,2]$. As the population with $\mathrm{CHB}$ ages, many patients will present with comorbidities and varying degrees of functional renal impairment [3-8], and approximately 2 to $15 \%$ of patients on hemodialysis have CHB [9]. Five nucleos(t)ide analogs (NUCs) are currently being used for the treatment of hepatitis B. NUC therapy had been shown to reverse fibrosis and cirrhosis and to reduce the risk of hepatic decompensation and hepatocellular carcinoma. Since NUCs do not eradicate the virus, most patients require long-term treatment. NUCs are generally safe and well tolerated, but side effects have been reported including lactic acidosis, myopathy, nephrotoxicity, neuropathy, and decrease in bone mineral density. Nephrotoxicity with adefovir or tenofovir has been the most commonly reported side effect. Nephrotoxicity manifesting as decrease in glomerular filtration rate (GFR) is more common in patients who are $>50$ years old, have baseline renal insufficiency, hypertension, and/or diabetes mellitus. Proximal renal tubular injury-resembling Fanconi's syndrome with hypophosphatemia, hypouricemia, aminoaciduria, and glycosuria-had also been reported. Consequently, the Guidelines of the European Association for the Study of the Liver (EASL) state that it seems appropriate for now to monitor for adverse renal effects with 
serum creatinine (estimated creatinine clearance) and serum phosphate levels during adefovir or tenofovir therapy in all $\mathrm{CHB}$ patients and with serum creatinine levels (estimated creatinine clearance) during nucleoside analogue therapy in $\mathrm{CHB}$ patients at high renal risk.

\section{Renal Abnormalities in HBV-Infected Patients}

2.1. Etiologies. $\mathrm{CHB}$ has been linked to renal disease for decades. Renal abnormalities (RA) associated with hepatitis $\mathrm{B}$ virus (HBV) may be of multiple origins. Glomerulonephritis (GN) is a well-described complication of chronic hepatitis B. HBV-associated glomerulonephritis has been frequently reported in the literature and the association of $\mathrm{HBV}$ and glomerulopathy is striking, especially in children with reported incidences of nephrotic syndrome, nephritic syndrome, and both of them in $64 \%, 57 \%$, and $35 \%$, respectively [10]. Epidemiological studies have shown that chronic carriage of HBV in adult individuals may lead to the development of nephrotic syndrome, the commonest histological type being membranous nephropathy $[11,12]$. In total, the different morphological forms of $\mathrm{HBV}$-associated renal injuries may include membranous nephropathy, membranoproliferative glomerulonephritis, mesangial proliferative glomerulonephritis, immunoglobulin A (IgA) nephropathy, focal segmental glomerulosclerosis, and polyarteritis nodosa [13].

Renal injury caused by HBV may be related to immune reactions, with glomerular deposition of immune complexes or virus-induced specific immunological effector mechanisms (specific $\mathrm{T}$ lymphocyte or antibody). Such reactions may damage the kidney or have indirect effects from virusinduced cytokines/mediators on renal tissue. HBV antigens (hepatitis B surface antigen (HBsAg) and hepatitis B core antigen ( $\mathrm{HBcAg}$ ) and $\mathrm{HBeAg}$ ) are also expressed in renal tubular epithelial cells. They can upregulate complement mediated inflammatory gene pathways and contribute to the pathogenesis of nephropathy [14]. Some circulating elements (cytokines, viruses, and antigens) may also impair renal function since the serum of patients with chronic HBV infection has been shown to induce apoptotic damage to the renal tubular cells [15]. Membranous glomerulonephritis (MGN) is the most common HBV-associated nephropathy. Of note, liver disease may be mild or even absent in those patients [16]. Membranoproliferative glomerulonephritis (MPGN) is characterised by the deposition of immune complexes in the mesangium and subendothelial spaces. Glomerular deposition of immunoglobulin G (IgG), complement C3, and HBsAg has been reported, with a predominant deposition of IgA in the renal mesangium in patients with $\mathrm{HBV}$-associated mesangial proliferative glomerulonephritis [17, 18]. Another mechanism is the so-called polyarteritis nodosa, a vasculitis affecting medium-sized arteries in most cases, which usually occurs within 4 months of $\mathrm{HBV}$ infection and affects the medium-sized arteries in most cases [19]. Some individuals with $\mathrm{HBV}$ infection may be genetically predisposed to develop nephropathy [20] and a recent study suggested that HBV infection with elevated alanine aminotransferase
(ALT), rather than HBV infection or elevated ALT alone, was significantly associated with reduced renal function, defined as an estimated glomerular filtration rate (GFR) lower than $60 \mathrm{~mL} / \mathrm{Min} / 1.73 \mathrm{~m}^{2}$ and/or albuminuria [21]. However, another study did not find this association [22].

Treatments used in chronic HBV may also be associated with renal abnormalities (hypophosphatemia, proximal tubulopathy, and renal acidosis) [23, 24]. In addition, potential comorbidities encountered in HBV patients (diabetes mellitus, high blood pressure, and HIV or HCV coinfection), some nonantiviral drugs that are commonly used (aminoglycosides, nonsteroidal anti-inflammatory drugs, and valproic acid), and patient age may impact renal function as well. Despite these multiple potential causes of renal alterations in chronic HBV patients, data on the prevalence of early diagnostic markers of kidney damage, proteinuria, and hematuria remain scanty.

2.2. Outcomes. Renal parameters are of utmost importance in $\mathrm{CHB}$ patients since renal dysfunction impacts clinical outcomes. In a prospective study including patients with HBV infection, the authors showed that an elevated serum creatinine at baseline was significantly associated with mortality rates at 6 months in multivariate analysis, with a hazard ratio (HR) for death of 5.23, almost as high as that of detectable HBV DNA (6.13) [25]. HBV infection increases the risk of occurrence of kidney disease in Chinese diabetic patients. Finally, in such patients with both kidney disease and HBV infection, besides the impact of kidney disease by itself on their prognosis, the therapeutic management of $\mathrm{HBV}$ infection is essential, while antiviral drugs dosages must be adjusted to renal function and potential renal toxicity of antivirals may further damage the kidneys and lead to clinical complications.

2.3. Prevalence of Renal Abnormalities. In a previous work, the efficacy, safety, and tolerability of two dosing regimens of adefovir have been investigated in two double-blind, placebocontrolled studies in patients with $\mathrm{CHB}$ and compensated liver disease who were not undergoing current treatment and who had evidence of HBV replication. The prevalence of proteinuria, hematuria, glycosuria, and hypophosphatemia was secondarily measured in the placebo group of 170 patients and was $17 \%, 30 \%, 8 \%$, and $10 \%$, respectively, evidencing that renal abnormalities occur even in the absence of antiretroviral treatment [26]. A cross-sectional study conducted in an HBV/HCV endemic area of southern Taiwan, however, reported no significant association between proteinuria and HBV infection, but the prevalence of proteinuria among HBs antigen-positive (HBsAg+) subjects was 6.4\% [27]. In another study, the prevalence of an abnormal GFR at baseline was determined in two cohorts of $145 \mathrm{CHB}$ patients planned to receive adefovir or placebo. In this study, the prevalence of a "mildly impaired" GFR, 50 to $80 \mathrm{~mL} / \mathrm{min}$, did not differ between the two groups: 39.6 versus $34.8 \mathrm{~mL} / \mathrm{min}$, respectively [28]. This result emphasizes that impaired renal function is highly prevalent in CHB patients, independently of any treatment with a potential nephrotoxicity. 
TABLE 1: International definition and stratification of kidney disease by the K/DOQI and the KDIGO.

\begin{tabular}{lcc}
\hline Stage & Description & $\mathrm{GFR}\left(\mathrm{mL} / \mathrm{min}^{\prime} / .73 \mathrm{~m}{ }^{2}\right)$ \\
\hline Patients at increased risk & Risk factors for kidney disease & More than 90 \\
1 & (e.g., diabetes, high blood pressure, family history, older age, etc.) & More than 90 \\
2 & Kidney damage and normal GFR & 60 to 89 \\
3 & Kidney damage and mild decrease in GFR & 30 to 59 \\
4 & Moderate decrease in GFR & 15 to 29 \\
5 & Severe decrease in GFR & Less than 15 \\
\hline
\end{tabular}

GFR: glomerular filtration rate; $\mathrm{CrCl}$ : creatinine clearance; signs of kidney damage may include proteinuria and hematuria.

Patients with chronic kidney disease (CKD) may have dysfunctions of their immune system, which makes them at a higher risk of infections. These dysfunctions result from phagocyte derived oxidative stress and sustained monocyte activation, mainly linked to accumulation of uraemic toxins [29]. The haemodialysis procedure may further increase the oxidative stress $[30,31]$. There are additional immunosuppressive factors in CKD patients, such as depressed peripheral lymphocyte count, impaired granulocyte phagocytic activity, anaemia, and malnutrition [32]. As a result, acute HBV infection is often mild or asymptomatic in CKD patients. Furthermore, these patients often become chronic carriers due to impaired viral clearance [33]. In some rare cases, the infection can progress to fibrosing cholestatic hepatitis, a fatal condition including cytopathic hepatic damage, in CKD patients [34].

For years, HBV infection has been a major concern in patients with end-stage renal disease (GFR is lower than $15 \mathrm{~mL} / \mathrm{min} / 1.73 \mathrm{~m}^{2}$ ), stage 5 of the international definition and stratification of CKD from the KDOQI-KDIGO (Kidney Disease Outcomes Quality Initiative-Kidney Disease Improving Global Outcomes) (Table 1) [35, 36]. However, several processes have been developed, promoted, and put in place in clinical practice, which led to a decline in the prevalence of HBV infection in the recent years. The prevalence of $\mathrm{HBV}$ infection, however, remains high in developing countries, up to $20 \%$, while it is now less than $10 \%$ in industrialized countries [37, 38]. HBV infection among CKD patients is still associated with higher morbidity and mortality in the absence of antiviral therapy by comparison with the general population $[37,38]$. Transplanted patients most of the time require long-term immunosuppression to prevent graft rejection, which can in turn favour HBV reactivation. Reactivation is characterised by an abrupt reappearance or rise in HBV DNA levels in the serum of patients with previously inactive or resolved HBV infection. It may be accompanied by reappearance of disease activity or flare-up of hepatitis [39]. As in hemodialysis patients, HBV infection is associated with decreased survival after renal transplantation and a more frequent need for retransplantation [40].

2.4. Risk Factors. Similarly to the general population, $\mathrm{CHB}$ patients may present with additional risk factors for developing CKD such as hypertension or diabetes. In one study, the prevalence of hypertension and diabetes at baseline in a population of $426 \mathrm{CHB}$ treatment-naïve patients was $4.9 \%$ and $15,0 \%$, respectively. However, the authors did not observe any significant difference in the occurrence of serum creatinine increase (greater than $0.5 \mathrm{mg} / \mathrm{dL}$ ) in patients with diabetes as compared to nondiabetics. The incidence of a serum creatinine increase was 5 times greater in hypertensive patients as compared to patients with normal blood pressure at baseline (1.6\% versus $0.3 \%$, resp.) [41]. In a retrospective cohort study of 80 United States community based CHB patients, before treatment initiation, $28 \%$ reported hypertension, $20 \%$ diabetes, $19 \%$ portal hypertension, $16 \%$ history of liver or kidney transplant, and $14 \%$ preexisting renal insufficiency [42]. In these patients the mean eGFR at baseline ranged from 84.41 to $87.72 \mathrm{~mL} / \mathrm{min} / 1.73 \mathrm{~m}^{2}$ (MDRD). In a prospective multicenter study in France, the Hepatitis B and Renal Parameters Evaluation (HARPE) study, among 268 patients without antiviral therapy at least 6 months prior to inclusion, $40.7 \%$ reported eGFR $<90 \mathrm{~mL} / \mathrm{min} / 1.73 \mathrm{~m}^{2}, 37.4 \%$ proteinuria, and $20 \%$ hematuria. According to CKD stages, $55.8 \%$ of patients presented renal abnormality and $27.3 \%$ had CKD stages 1 to 3 [43]. In that population, 38.8\% presented dyslipidemia, $9.2 \%$ hypertension, and $4.6 \%$ diabetes mellitus as comorbidities.

\section{Anti-HBV Drugs and Renal Dysfunction}

3.1. Nucleotide Analogues. Nucleotide analogues have been associated with putative renal toxicity which is related to an accumulation of the nucleotides metabolites in renal tubular cells. This toxicity is more frequent with cidofovir than with adefovir and with adefovir more than with tenofovir.

3.1.1. Adefovir. Two double-blind, placebo-controlled studies, GS-98-437 and GS-98-438, have been performed in patients with $\mathrm{CHB}$ and compensated liver disease, who were not undergoing current treatment and who had evidence of $\mathrm{HBV}$ replication. The efficacy, the renal safety, and the tolerability of two dosing regimens of adefovir (ADV), $10 \mathrm{mg}$ daily or $30 \mathrm{mg}$ daily, were evaluated [26]. The authors reported that ADV $10 \mathrm{mg}$ was nonnephrotoxic, with an incidence of renal events similar to that observed in the placebo group: $10 \%$ and $12 \%$, respectively. ADV $30 \mathrm{mg}$ was shown to be nephrotoxic, with an incidence of $35 \%$ for renal events. Of 
interest, renal abnormalities were frequently observed in patients from the placebo control groups, either were they $\mathrm{HBeAg}$-positive or HBeAg-negative. Proteinuria, hematuria, and glycosuria (ranging from grades 1 to 4 ) were thus reported in $28 \%, 49 \%$, and $13 \%$, respectively, of the placebotreated patients. Two additional studies [44, 45] reported a complete analysis on the safety and efficacy of 48 weeks of ADV in patients with $\mathrm{HBeAg}$-positive and $\mathrm{HBeAg}$-negative CHB. ADV $10 \mathrm{mg}$ daily was well tolerated and significantly improved histologic findings in the liver, reduced serum HBV DNA levels, normalized ALT levels, and induced HBeAg loss and seroconversion in a diverse multicentre population. In these two double-blind randomized, placebo-controlled studies, ADV did not induce renal abnormalities at the dose of $10 \mathrm{mg}$ compared with placebo. However, the European VIRGIL cohort reported different findings. In this cohort study, normal kidney function (GFR $>80 \mathrm{~mL} / \mathrm{min}$ ) was found in $81 \%$ of $\mathrm{CHB}$ patients before the start of any antiviral therapy. $15 \%$ and $4 \%$ showed mild (GFR $50-80 \mathrm{~mL} / \mathrm{min}$ ) or moderate renal impairment (GFR $<50 \mathrm{~mL} / \mathrm{min})$. During therapy, ADV $10 \mathrm{mg}$-exposed patients showed an increase of mean serum creatinine levels of $34 \%$ as compared to baseline values while mean creatinine levels did not change by more than $10 \%$ in patients treated with lamivudine, entecavir, and tenofovir. There was no significant difference concerning early tubular changes between treated and untreated patients [46].

In another recent retrospective study, the incidence and factors associated with renal dysfunction and hypophosphatemia in patients with $\mathrm{CHB}$ on long-term treatment with ADV and lamivudine (LAM) were investigated. 292 patients, treated with ADV $10 \mathrm{mg} /$ day and LAM $100 \mathrm{mg} /$ day for at least 6 months, were included. During a median treatment duration of 64 months, $9.6 \%$ of the patients developed renal impairment (defined as eGFR $<50 \mathrm{~mL} / \mathrm{min} / 1.73 \mathrm{~m}^{2}$ ) and 73 (27.1\%) developed hypophosphatemia, which was persistent in 1 of 5 patients. The cumulative incidences of renal impairment at 1,3 , and 5 years were $1.4 \%, 7.5 \%$, and $10.5 \%$, respectively. Those of hypophosphatemia were $6.8 \%, 20.6 \%$, and $26.7 \%$, respectively. Multivariate analysis identified old age, liver cirrhosis, and hypertension as determinants of the ADV/LAM renal toxicity and male sex, hepatocellular carcinoma, and low baseline serum phosphate as determinants of ADV/LAM-induced hypophosphatemia. Three of the 14 patients with persistent hypophosphatemia developed Fanconi's syndrome [47].

3.1.2. Tenofovir. Tenofovir (TDF), which shares several chemical and mechanistical features with ADV, has early been reported as being potentially toxic to the kidneys. However, a recent meta-analysis included 8 studies and 7496 patients with HIV infection. It showed that the risk for ARF was $0.7 \%$ higher (95\% confidence interval (95\% CI) [0.2-1.2]) in TDF-treated patients than in patients receiving a combined antiretroviral treatment (cART) without TDF [48]. Nevertheless, this meta-analysis also included 11 studies to estimate TDF chronic nephrotoxicity. It included 5767 patients, treated for a mean of 48 weeks (24 to 144 weeks).
TDF-treated patients experienced a decrease in estimated creatinine clearance (eCrCl, Cockcroft and Gault formula) of $3.92 \mathrm{~mL} / \mathrm{min} / 1.73 \mathrm{~m}^{2}$ (95\% CI [2.13-5.70]) compared to nonTDF-treated patients. Although judged as "moderate" by the author, such a decline in renal function over the relatively short period of treatment of the studies that were included (less than a year on average) should on the contrary be considered as quite significant. In fact, patients can now be prescribed TDF for several decades in HIV, and also for a longer period of time in $\mathrm{CHB}$, and a loss of kidney function of about $4 \mathrm{~mL} / \mathrm{min} / 1.73 \mathrm{~m}^{2}$ in a year is clinically significant.

A retrospective cohort compared more than 6500 TDFexposed patients with 4000 nonexposed patients between 1997 and 2007 (38,132 person-year of follow-up, median follow-up $>3.9$ years) [49]. The hazard ratios (HR) for proteinuria (two consecutive dipsticks showing proteinuria $>$ $30 \mathrm{mg} / \mathrm{dL}$ ), rapid kidney function decline (eGFR decline > $3 \mathrm{~mL} / \mathrm{min} /$ year using MDRD equation), or CKD (eGFR < $60 \mathrm{~mL} / \mathrm{min}$ ) were $1.30,1.17$, and 1.44 per year of TDF exposure, respectively (95\% CI: [1.22-1.37], [1.11-1.24], and $[1.30-1.60]$, resp.). The risk of CKD was doubled in patients ever exposed to TDF (eGFR $<60 \mathrm{~mL} / \mathrm{min}$; 95\% CI [1.76-2.54]).

In another study, the risk of progression from CKD stages $0-1$ to stage 2 or 3 was higher in naive patients exposed to TDF than in TDF-free patients $(48.8 \%$ versus $23.7 \%$; $P<$ 0.001 for CKD stage 2 and $5.8 \%$ versus $0.0 \%$; $P=0.028$ for CKD stage 3) [50]. TDF treatment was the only independent factor associated with progression to CKD stage 2 (HR 2.12; 95\% CI [1.41-3.18]) and to CKD stage 3 (HR 4.91; 95\% CI [1.02-23.7]).

In CHB patients, TDF has shown similar safety profile as in HIV-positive patients. Although the clinical experience in $\mathrm{HIV}$ with this drug is greater, there is no expected difference in terms of safety in CHB patients [51-53].

Several cohort studies, but not all, have suggested that renal impairment was more frequently reported in $\mathrm{CHB}-$ treated patients when ADV- (or TDF-) including regimens were used. In one monocentric cohort study including more than $300 \mathrm{CHB}$-treated patients, renal deterioration under treatment was rare during therapy (around 5\% of patients had an increase of at least $5 \%$ of the creatinine level), but such a deterioration was attributable to $75 \%$ of nucleotide-including regimen as compared to $25 \%$ of nucleoside-including regimen and results were similar when comparing TDF to entecavir [54].

It thus appears that TDF and ADV share a similar renal toxicity profile, including two recently reported cases of Fanconi's disease in monoinfected HBV patients $[55,56]$.

\subsection{Nucleoside Analogues}

3.2.1. Lamivudine. In HIV patients, only rare cases of lamivudine-induced tubular dysfunction have been reported [57]. In CHB patients, the renal tolerance of LAM has not been extensively studied until recently, in particular in the GLOBE trial of telbivudine, which will be detailed further in the telbivudine section below. 
3.2.2. Entecavir. Entecavir is also considered to be nonnephrotoxic. Rare cases of lactic acidosis have been reported in one series of CHB patients with severely impaired liver function (Model for End-Stage Liver Disease (MELD) score of at least 20) [58].

3.2.3. Telbivudine. Telbivudine (LDT) is a nucleoside analogue used in the treatment of CHB. In a recently published retrospective study from China, the renal safety of LDT was compared to that of ADV, in both cases used as monotherapy for one year, in CHB patients [59]. This retrospective analysis involved 101 patients with $\mathrm{CHB}$ and liver cirrhosis. The mean changes in serum creatinine at week 52 from baseline were $+0.05 \mathrm{mg} / \mathrm{dL}$ in the ADV group and $-0.12 \mathrm{mg} / \mathrm{dL}$ in the LDT group, the difference between the two groups being highly statistically significant $(P=$ 0.000 ). The median change in eGFR at week 52 from baseline also differed significantly between the ADV and LDT groups $\left(-4.09\right.$ versus $\left.+18.32 \mathrm{~mL} / \mathrm{min} / 1.73 \mathrm{~m}^{2}, P=0.000\right)$. Interestingly, the decline in eGFR observed with $\mathrm{ADV}$ was of a similar magnitude as that previously reported with TDF that is around $4 \mathrm{~mL} / \mathrm{min} / 1.73 \mathrm{~m}^{2} /$ year. In addition, a potential renoprotective effect of LDT was observed with $92 \%$ of the patients with a baseline eGFR $<90 \mathrm{~mL} / \mathrm{min} / 1.73 \mathrm{~m}^{2}$ shifting to eGFR $\geq 90 \mathrm{~mL} / \mathrm{min} / 1.73 \mathrm{~m}^{2}$ after 52 weeks of LDT treatment, as compared to $38 \%$ in the ADV group. The proportion of patients with eGFR $\geq 90 \mathrm{~mL} / \mathrm{min} / 1.73 \mathrm{~m}^{2}$ in the LDT group increased from $76.4 \%$ at baseline to $94.6 \%$ at week 52 , while that in the ADV group decreased from $82.6 \%$ at baseline to $78.3 \%$ at week 52 .

These retrospective observations, showing a better renal safety of LDT, were confirmed in the prospective Phase III GLOBE trial, over 2 and 4 years of treatment $[60,61]$. After 2 years of treatment, LDT showed a better efficacy as compared to LAM. At year 2, the eGFR in LDT-treated patients had increased from $94.9 \mathrm{~mL} / \mathrm{min} / 1.73 \mathrm{~m}^{2}$ at baseline, to $112.3 \mathrm{~mL} / \mathrm{min} / 1.73 \mathrm{~m}^{2}$ at week $104(P<0.0001)$, which results in an increase of $17.4 \mathrm{~mL} / \mathrm{min} / 1.73 \mathrm{~m}^{2}$. At week 208, the eGFR remained stable as compared to week 104, at $109.9 \mathrm{~mL} / \mathrm{min} / 1.73 \mathrm{~m}^{2}$, which results in mean absolute and relative increases of $14.9 \mathrm{~mL} / \mathrm{min} / 1.73 \mathrm{~m}^{2}$ and $16.6 \%$, respectively, as compared to baseline. Furthermore, in the subpopulation of LDT-treated patients with mildly reduced baseline eGFR of $60-90 \mathrm{~mL} / \mathrm{min} / 1.73 \mathrm{~m}^{2}, 74 \%$ of them shifted to eGFR $>90 \mathrm{~mL} / \mathrm{min} / 1.73 \mathrm{~m}^{2}$ after 4 years of treatment.

Patients treated with LAM during the first 2 years of the GLOBE study also showed an increase in their eGFR, from $93.95 \mathrm{~mL} / \mathrm{min} / 1.73 \mathrm{~m}^{2}$ at baseline to $99.5 \mathrm{~mL} / \mathrm{min} / 1.73 \mathrm{~m}^{2}$ at 2 years (difference $5.55 \mathrm{~mL} / \mathrm{min} / 1.73 \mathrm{~m}^{2}$ ); however this was thrice lower as compared to the increase observed in the LDT group: 5.55 versus $17.4 \mathrm{~mL} / \mathrm{min} / 1.73 \mathrm{~m}^{2}$. Amongst patients treated with LAM for 2 years, those who switched to LDT for an additional 2-year treatment showed an additional increase in their eGFR of $11.93 \mathrm{~mL} / \mathrm{min} / 1.73 \mathrm{~m}^{2}$ ( $+9.6 \%$ at 4 weeks, 208 as compared to time of switch).

The mechanism underlying the effect of LDT on renal function is not known; however, based on clinical and experimental observations, one could hypothesize about the cell

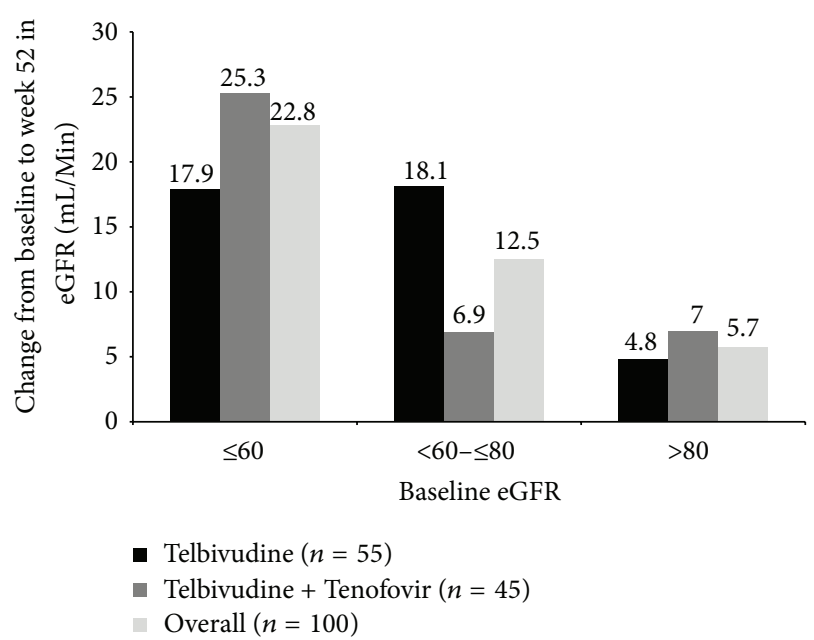

FIGURE 1: Week 52 glomerular filtration rate (MDRD) changes, by baseline rate and treatment (efficacy population) in the Roadmap multinational, phase IV, single-arm, open-label study (ClinicalTrials.gov ID NCT00651209).

biological context within which LDT might exert its effect. At any given time, renal function is determined by the number of functioning nephrons. During development of CKD, the number of functioning nephrons progressively decreases. The loss of nephrons generally is quite considerable before renal function is affected and early damage to the kidney can easily be missed. This is due to the fact that the remaining nephrons functionally compensate for the lost ones. However, the compensatory capacity of individual nephrons eventually has its limits and a decreased renal function only becomes apparent once their number is too low (at least 50 to $75 \%$ of nephrons lost). In chronic renal injury, nephron loss is slow and it may take several years (even decades) before being clinically noticeable.

Both the clinical and experimental observations of LDT on renal function comply with the characteristics expected for a compound involved in stimulating renal repair. First, LDT's beneficial effect on renal function in CKD patients on average is not noticed until 9 months of treatment. This delay is consistent with the fact that one would expect if injured nephrons are stimulated towards repair because cellular repair in a CKD condition might be slow due to the uremic environment and, in addition, it might take time for a sufficient number of nephrons to be repaired such that there is a measurable effect on renal function. The second element suggesting that LDT might aid or drive injured nephrons in their repair is provided by the fact that the maximal increase in renal function seemingly depends on the eGFR at the start of LDT treatment. In fact, patients with eGFR above $80 \mathrm{~mL} / \mathrm{min}$ show a maximum benefit of approximately $5 \%$ of baseline eGFR whereas subjects with eGFR between 60 and $80 \mathrm{~mL} / \mathrm{min} / 1.73 \mathrm{~m}^{2}$ have a benefit of around $18 \%$ (Figure 1) [62]. Indeed in some diseased conditions the population of nephrons susceptible to stimulated repair by telbivudine might be higher; hence their repair has a greater impact on measurable renal function. A third argument 
corroborating the above reasoning is the fact that telbivudine does not improve renal function in patients with normal renal function and has neither morphological nor functional effect in normal rats, indicating that healthy nephrons are not susceptible to LDT and that the actions of LDT might be particularly expressed by their effect on injured nephrons. This hypothesis even holds if one considers that patients with normal eGFR already might present a relevant population of injured nephrons in their kidneys due to the delay by which progressive nephron loss is noted on renal function. Repair of this population would not be noticed on eGFR, as renal function would already be in its maximum due to compensation, which is consistent with the clinical data. Furthermore, the beneficial effect of LDT on renal function reaches a plateau and improvements in renal function are stable for up to 6 years of continuous LDT treatment. These observations are consistent with the view that once maximum nephron repair is achieved, the kidney is left with only normal nephrons which are not susceptible to telbivudine. This is consistent with the hypothesis that LDT is able to facilitate renal repair of injured nephrons.

Overall, it is clear that there is evidence supporting that LDT (1) is able to induce structural and beneficial changes in the kidney, besides and independently from its antiviral activity, and (2) might exert its renal effects by stimulating repair of injured nephrons. A direct effect is, however, unlikely, since LDT is an antireverse transcriptase drug and inhibition of reverse transcriptase activity particularly has detrimental effects. Hence, an indirect mechanism seems more likely. Such indirect mechanisms could involve LDT interfering with telomerase activity (i.e., human reverse transcriptase) specifically in cells that can drive fibrosis. For instance, fibroblasts tend to have an increased telomerase activity during fibrosis. Their suppression might alleviate injurious pressure on injured cells, allowing natural repair. Interfering with mitochondrial activity could also be hypothesized, specifically in cells that can drive fibrosis, for example, activated fibroblasts, which need more energy. Interference of LDT with mitochondrial function might also suppress progression of fibrosis and nephron loss, thus allowing natural repair. Inflammation being a critical process in the development and progression of $\mathrm{CKD}$, a potential effect of LDT on inflammation could also be one mechanism by which LDT could stimulate the repair of injured cells.

\section{Renal Follow-Up of CHB Patients}

4.1. Complete Baseline Renal Evaluation. A regular followup of the renal function of $\mathrm{CHB}$ patients is important to ensure appropriate global care, namely, dosage adjustment and potential switch or addition in case of safety or resistance issue. Interpretation of follow-up tests results requires a baseline thorough renal evaluation to serve as a reference, especially before any antiviral treatment is initiated. As a result, at time of diagnosis, the renal evaluation should comprise a calculation of the eGFR together with a urinary dipstick to search for potential markers of organic kidney damage, such as proteinuria or hematuria. eGFR calculation should be performed with the MDRD formula, which is the recommended formula for both kidney disease diagnosis and drug dosage adjustment purposes in adults [63] (Table 1). In addition to CKD screening at baseline, the evaluation of the eGFR before initiating the treatment will allow starting antiviral therapy at appropriate doses, reduced when necessary, in patients with an eGFR below $60 \mathrm{~mL} / \mathrm{min} / 1.73 \mathrm{~m}^{2}$.

Specific attention should be given to the tubular function in $\mathrm{CHB}$ patients. Since both the HBV infection and its treatments may induce tubular dysfunction, and in some cases complete Fanconi's syndrome, a baseline evaluation of the tubular function is also required. This latter should include the following tests in blood and urine: serum potassium, uric acid, phosphorus, bicarbonates, glucose, and calcium; urinary sediment, glycosuria, and proteinuria, at baseline, as part of the global baseline renal evaluation in $\mathrm{CHB}$ patients.

4.2. Follow-Up Renal Evaluation. The follow-up of the renal function of treated CHB patients will allow early detection of renal changes, as compared to baseline data.

In all patients with normal baseline renal evaluation and with antiviral therapy with no renal impact, we recommend renal work-up to be performed once a year. In patients for whom the antiviral treatment comprises an antiviral drug known to be potentially nephrotoxic (essentially ADV and TDF), the Summary of Product Characteristics (SmPC) recommends a monthly evaluation of serum creatinine, glomerular filtration rate (GFR), and phosphorus for the first year and then an evaluation every 3 months. Since such recommendation is difficult to implement in real clinical practice, the European Association for the Study of the Liver (EASL) recommends renal follow-up every 1-3 months during the first year and every 3-6 months thereafter [64] (Figure 2).

For any persistent sign of renal damage at 2 consecutive evaluations, the patient should be referred to a nephrologist for further renal explorations. Specific attention should be given to high-risk patients such as those with decompensated cirrhosis, baseline eGFR $<60 \mathrm{~mL} / \mathrm{min} / 1.73 \mathrm{~m}^{2}$, high blood pressure, proteinuria, diabetes mellitus, glomerulonephritis, organ transplant, and/or receiving concomitant nephrotoxic drugs.

4.3. Antiviral Drugs Management in Case of CKD. In patients with CKD, the pharmacokinetics of drugs may be significantly modified due to the reduced elimination of active species (unchanged drug or metabolites) by both reduced renal excretion and altered metabolism. In case renal impairment is not diagnosed and/or drugs dosages not appropriately adjusted to the level of renal function, the administration of inappropriately large doses may lead to acute or cumulative toxicity. Conversely, a larger-than-recommended reduction in drugs dosage may in turn lead to subtherapeutic dosing, treatment failure, and prolonged illness $[65,66]$. In case of $\mathrm{CHB}$ patients, this question is key for a successful treatment, both in terms of efficacy and tolerance, since all antivirals require dosage modifications in $\mathrm{CKD}$ patients, according to the eGFR at time of administration (Tables 2-6) [67]. In 


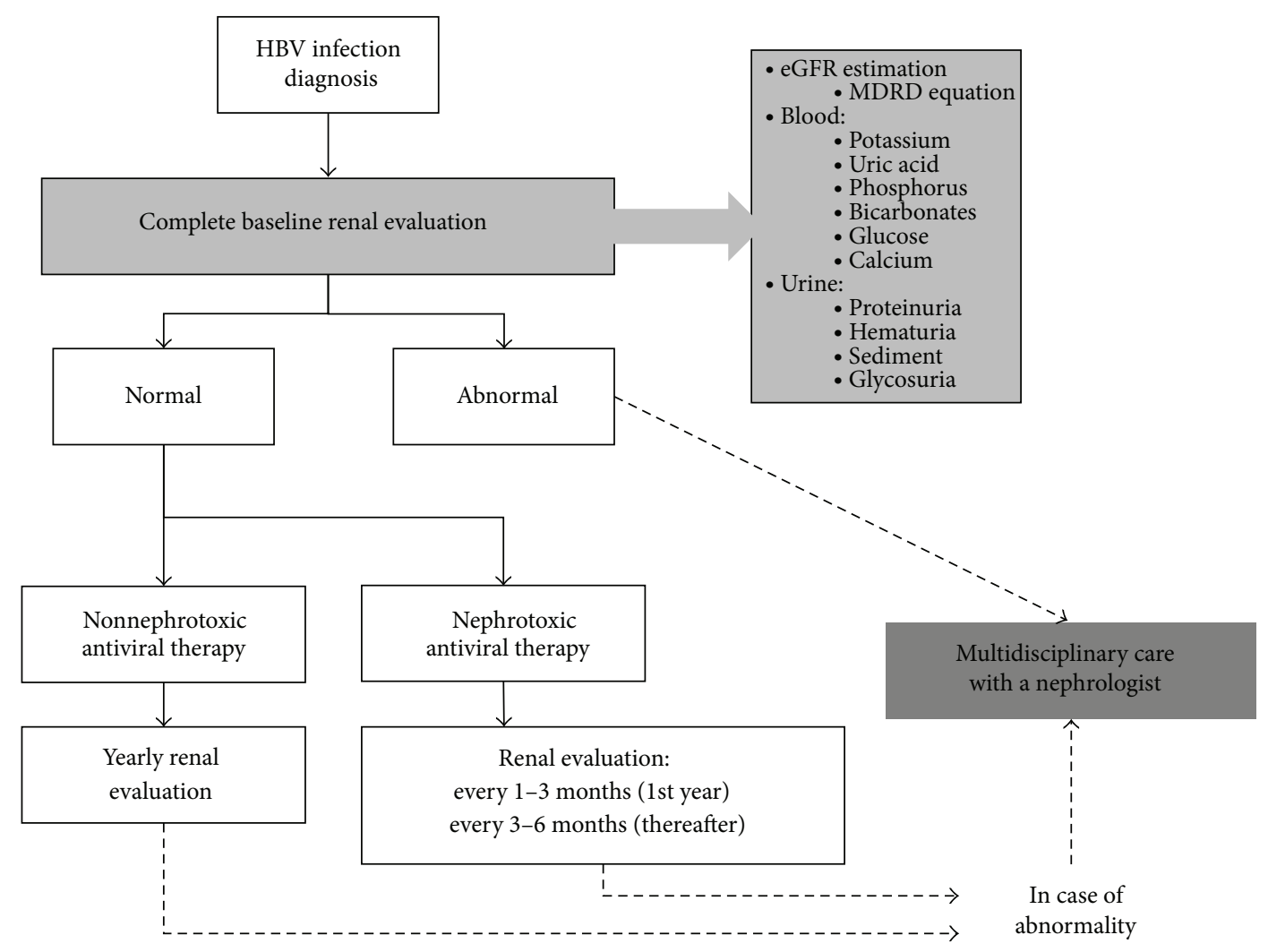

FIgURE 2: Renal baseline evaluation and follow-up in CHB patients.

TABLE 2: Drug dosing recommendations for adefovir in CHB patients with CKD.

\begin{tabular}{lc}
\hline eGFR $(\mathrm{mL} / \mathrm{Min})$ & Dosage recommended \\
\hline$\geq 90$ & $10 \mathrm{mg} /$ day \\
$<90-50$ & $10 \mathrm{mg} /$ day \\
$<50-20$ & $10 \mathrm{mg}$ every 48 hours \\
$<20-10$ & $10 \mathrm{mg}$ every 72 hours \\
$<10$ & $10 \mathrm{mg}$ once a week \\
HD & 10 mg once a week \\
CAPD & ND
\end{tabular}

${ }^{*}$ In hemodialysis patients, adefovir should be administered on a hemodialysis day, after the session.

eGFR: estimated glomerular filtration rate; ND: no data.

Source: http://www.sitegpr.com/.

patients with CKD, drugs with the lowest potential for renal toxicity should be preferred and known nephrotoxic drugs withheld.

\section{Conclusion}

The prevalence of $\mathrm{CKD}$ in $\mathrm{CHB}$ patients is high, both in patients treated with antiviral drugs and in nontreated patients. NUCs are very potent agents, with a fair resistance profile, at least for the second generation drugs. While nucleosides analogues (LAM, entecavir) have no renal impact, nucleotides analogues (ADV and TDF) may have renal
TABLE 3: Drug dosing recommendations for tenofovir in CHB patients with CKD.

\begin{tabular}{lc}
\hline eGFR (mL/Min) & Dosage recommended \\
\hline$\geq 90$ & $300 \mathrm{mg} /$ day \\
$<90-50$ & $300 \mathrm{mg} /$ day \\
$<50-30$ & $300 \mathrm{mg}$ every 48 hours \\
$<30-15$ & $300 \mathrm{mg}$ every 72 to 96 hours \\
& or $300 \mathrm{mg}$ twice a week \\
$<15$ & $300 \mathrm{mg}$ once a week \\
HD $^{*}$ & $300 \mathrm{mg}$ once a week \\
CAPD &
\end{tabular}

${ }^{*}$ In hemodialysis patients, tenofovir should be administered on a hemodialysis day, after the session.

eGFR: estimated glomerular filtration rate; ND: no data. Source: http://www.sitegpr.com/.

tolerance issues which necessitate a specific follow-up even if tubular dysfunction is rare and may be probably treated more by dose adjustment according to trough serum levels rather than by switching to another drug.

LDT, the most recent antiviral drug, having shown interesting efficacy results, also demonstrated a favourable renal safety profile. Not only is LDT nonnephrotoxic, but it may also exhibit renoprotective effects in patients showing decreased renal function before treatment is initiated. This renoprotective effect has been demonstrated in patients 
TABLE 4: Drug dosing recommendations for lamivudine in CHB patients with CKD.

\begin{tabular}{lcc}
\hline \multirow{2}{*}{ eGFR (mL/Min) } & \multicolumn{2}{c}{ Dosage recommended } \\
& First dose & Maintenance \\
\hline$\geq 90$ & $100 \mathrm{mg}$ & $100 \mathrm{mg} /$ day \\
$<90-60$ & $100 \mathrm{mg}$ & $100 \mathrm{mg} /$ day \\
$<60-30$ & $100 \mathrm{mg}$ & $50 \mathrm{mg} /$ day \\
$<30-15$ & $100 \mathrm{mg}$ & $25 \mathrm{mg} /$ day \\
$<15$ & $35 \mathrm{mg}$ & $10-15 \mathrm{mg} /$ day \\
HD* & $35 \mathrm{mg}$ & $10-15 \mathrm{mg} /$ day \\
CAPD & $35 \mathrm{mg}$ & $10 \mathrm{mg} /$ day \\
\hline
\end{tabular}

${ }^{*}$ On hemodialysis days, lamivudine should be administered after the session.

eGFR: estimated glomerular filtration rate.

Source: http://www.sitegpr.com/.

TABLE 5: Drug dosing recommendations for entecavir in $\mathrm{CHB}$ patients with CKD.

\begin{tabular}{lcc}
\hline $\begin{array}{l}\text { eGFR } \\
(\mathrm{mL} / \text { Min })\end{array}$ & \multicolumn{2}{c}{ Dosage recommended } \\
& Usual dose & Lamivudine-resistant patients \\
\hline$\geq 90$ & $0.5 \mathrm{mg} /$ day & $1 \mathrm{mg} /$ day \\
$<90-50$ & $0.5 \mathrm{mg} /$ day & $1 \mathrm{mg} /$ day \\
$<50-30$ & $0.5 \mathrm{mg}$ every 48 hours & $0.5 \mathrm{mg} /$ day \\
$<30-10$ & $0.5 \mathrm{mg}$ every 72 hours & $0.5 \mathrm{mg}$ every 48 hours \\
$<10$ & $0.5 \mathrm{mg}$ once a week & $0.5 \mathrm{mg}$ every 72 hours \\
HD & $0.5 \mathrm{mg}$ once a week & $0.5 \mathrm{mg}$ every 72 hours \\
CAPD & $0.5 \mathrm{mg}$ once a week & $0.5 \mathrm{mg}$ every 72 hours \\
\hline
\end{tabular}

${ }^{*}$ In hemodialysis patients, entecavir should be administered on a hemodialysis day, after the session.

eGFR: estimated glomerular filtration rate.

Source: http://www.sitegpr.com/.

TABLE 6: Drug dosing recommendations for telbivudine in $\mathrm{CHB}$ patients with CKD.

\begin{tabular}{lcc}
\hline \multirow{2}{*}{ eGFR (mL/Min) } & \multicolumn{2}{c}{ Dosage recommended } \\
& Oral solution & Tablets \\
\hline$\geq 90$ & $600 \mathrm{mg} /$ day & $600 \mathrm{mg} /$ day \\
$<90-60$ & $600 \mathrm{mg} /$ day & $600 \mathrm{mg} /$ day \\
$<60-30$ & $400 \mathrm{mg} /$ day & $600 \mathrm{mg}$ every 48 hours \\
$<30-15$ & $200 \mathrm{mg} /$ day & $600 \mathrm{mg}$ every 72 hours \\
$<15$ & $120 \mathrm{mg} /$ day & $600 \mathrm{mg}$ every 96 hours \\
HD & $120 \mathrm{mg} /$ day & $600 \mathrm{mg}$ every 96 hours \\
CAPD & ND & ND \\
\hline
\end{tabular}

* On hemodialysis days, telbivudine should be administered after the session.

eGFR: estimated glomerular filtration rate; ND: no data.

Source: http://www.sitegpr.com/.

naïve of previous antiviral treatment in the GLOBE trial. Furthermore, the extension study of the GLOBE trial showed that even patients who had been previously treated with LAM benefited from the renoprotective effect of LDT, with an additional increase in their eGFR of around $10 \%$.
With renal safety having been the main treatment-related concern during the past years in CHB patients, LDT offers very interesting efficacy and safety properties, which may make it the drug of choice in the near future for high-risk patients such as those with decompensated cirrhosis, baseline eGFR $<60 \mathrm{~mL} / \mathrm{Min} / 1.73 \mathrm{~m}^{2}$, high blood pressure, proteinuria, diabetes mellitus, glomerulonephritis, organ transplant, and/or receiving concomitant nephrotoxic drugs.

\section{Abbreviations}

\begin{tabular}{|c|c|}
\hline CHB: & Chronic hepatitis B \\
\hline NUCs: & Nucleos(t)ide analogs \\
\hline RA: & Renal abnormalities \\
\hline HBV: & Hepatitis B virus \\
\hline GN: & Glomerulonephritis \\
\hline HBsAg: & Hepatitis B surface antigen \\
\hline HBcAg: & Hepatitis B core antigen \\
\hline HBeAg: & Hepatitis B core antigen \\
\hline MGN: & Membranous glomerulonephritis \\
\hline MPGN: & $\begin{array}{l}\text { Membranoproliferative } \\
\text { glomerulonephritis }\end{array}$ \\
\hline IgG: & Immunoglobulin G \\
\hline IgA: & Immunoglobulin A \\
\hline ALT: & Alanine aminotransferase \\
\hline GFR: & Glomerular filtration rate \\
\hline eGFR: & Estimated glomerular filtration rate \\
\hline CKD: & Chronic kidney disease \\
\hline KDOQI-KDIGO: & $\begin{array}{l}\text { Kidney Disease Outcomes Quality } \\
\text { Initiative-Kidney Disease Improving } \\
\text { Global Outcomes }\end{array}$ \\
\hline RRT: & Renal replacement therapy \\
\hline ADV: & Adefovir \\
\hline LAM: & Lamivudine \\
\hline TDF: & Tenofovir/tenofovir disoproxil fumarate \\
\hline cART: & Combined antiretroviral treatment \\
\hline eCrCl: & Estimated creatinine clearance \\
\hline LDT: & Telbivudine \\
\hline SmPC: & Summary of Product Characteristics \\
\hline EASL: & $\begin{array}{l}\text { European Association for the Study of } \\
\text { the Liver. }\end{array}$ \\
\hline
\end{tabular}

\section{Conflict of Interests}

Gilbert Deray is Speaker at Novartis and Gilead. Ji-Dong Jia is Advisory Board Member for Bristol Myers Squibb, Novartis, Roche, and MSD. Teerha Piratvisuth received Research Grant from Roche, Bristol Myers Squibb, MSD, and Novartis and Advisory Board Member for Roche, MSD, Novartis, and Gilead. Henry Lik Yuen Chan is Advisor for Bristol Myers Squibb, Gilead, Novartis, Roche, and MSD and received honorarium for lecture from Abbott, Bristol Myers Squibb, Echosens, Gilead, Glaxo-SmithKline, Novartis, Roche, and MSD and unrestricted grant from Roche for HBV research. Stanislas Pol is Speaker at Glaxo-SmithKline, Bristol Myers Squibb, Boehringer Ingelheim, Janssen Gilead, Roche, MSD, Sanofi, Novartis, Vertex, and Abbvie, received grants from Bristol Myers Squibb, Gilead, Roche, and MSD, and is Board Member for Glaxo-SmithKline, Bristol Myers Squibb, 
Boehringer Ingelheim, Janssen, Gilead, Roche, MSD, Sanofi, Novartis, Vertex, and Abbvie.

\section{References}

[1] B. J. McMahon, "Epidemiology and natural history of hepatitis B," Seminars in Liver Disease, vol. 25, supplement 1, pp. 3-8, 2005.

[2] D. Lavanchy, "Hepatitis B virus epidemiology, disease burden, treatment, arid current and emerging prevention and control measures," Journal of Viral Hepatitis, vol. 11, no. 2, pp. 97-107, 2004.

[3] K. N. Lai, P. K. T. Li, S. F. Lui et al., "Membranous nephropathy related to hepatitis B virus in adults," The New England Journal of Medicine, vol. 324, no. 21, pp. 1457-1463, 1991.

[4] K. Deterding, N. Lampe, J. Reijnders et al., "Prevalence and severity of kidney dysfunction in patients with chronic hepatitis B in Europe: data from the European VIRGIL cohort," in Proceedings of the 46th Annual Meeting of the European Association for the Study of the Liver (EASL '11), Berlin, Germany, MarchApril 2011.

[5] N. B. Ha, R. T. Garcia, H. N. Trinh et al., "Renal dysfunction in chronic hepatitis B patients treated with adefovir dipivoxil," Hepatology, vol. 50, no. 3, pp. 727-734, 2009.

[6] K. N. Lai, P. K. T. Li, S. F. Lui et al., "Membranous nephropathy related to hepatitis B virus in adults," The New England Journal of Medicine, vol. 324, no. 21, pp. 1457-1463, 1991.

[7] K. Deterding, N. Lampe, J. Reijnders et al., "Prevalence and severity of kidney dysfunction in patients with chronic hepatitis B in Europe: data from the European VIRGIL cohort," in Proceedings of the 46th Annual Meeting of the European Association for the Study of the Liver (EASL '11), Berlin, Germany, March 2011.

[8] N. B. Ha, N. B. Ha, R. T. Garcia et al., "Renal dysfunction in chronic hepatitis B patients treated with adefovir dipivoxil," Hepatology, vol. 50, no. 3, pp. 727-734, 2009.

[9] F. Fabrizi, P. Messa, and P. Martin, "Hepatitis B virus infection and the dialysis patient," Seminars in Dialysis, vol. 21, no. 5, pp. 440-446, 2008.

[10] S. O. Ozdamar, S. Gucer, and K. Tinaztepe, "Hepatitis-B virus associated nephropathies: a clinicopathological study in 14 children," Pediatric Nephrology, vol. 18, no. 1, pp. 23-28, 2003.

[11] R. Bhimma and H. M. Coovadia, "Hepatitis B virus-associated nephropathy," American Journal of Nephrology, vol. 24, no. 2, pp. 198-211, 2004.

[12] Z. Yi, Y. W. Jie, and Z. Nan, “The efficacy of anti-viral therapy on hepatitis b virus-associated glomerulonephritis: a systematic review and meta-analysis," Annals of Hepatology, vol. 10, no. 2, pp. 165-173, 2011.

[13] E. C. Chacko, S. K. Surrun, T. P. M. Sani, and J. M. Pappachan, "Chronic viral hepatitis and chronic kidney disease," Postgraduate Medical Journal, vol. 86, no. 1018, pp. 486-492, 2010.

[14] J. Ren, L. Wang, Z. Chen et al., "Gene expression profile of transgenic mouse kidney reveals pathogenesis of hepatitis B virus associated nephropathy," Journal of Medical Virology, vol. 78 , no. 5, pp. 551-560, 2006.

[15] C. L. Deng, X. W. Song, H. J. Liang, C. Feng, Y. J. Sheng, and M. Y. Wang, "Chronic hepatitis B serum promotes apoptotic damage in human renal tubular cells," World Journal of Gastroenterology, vol. 12, no. 11, pp. 1752-1756, 2006.
[16] T. J. Liang, "Hepatitis B: the virus and disease," Hepatology, vol. 49, supplement 5, pp. S13-S21, 2009.

[17] J. Nagy, G. Bajtai, H. Brasch et al., "The role of hepatitis B surface antigen in the pathogenesis of glomerulopathies," Clinical Nephrology, vol. 12, no. 3, pp. 109-116, 1979.

[18] R. Bhimma, H. M. Coovadia, and M. Adhikari, "Hepatitis B virus-associated nephropathy in black South African children," Pediatric Nephrology, vol. 12, no. 6, pp. 479-484, 1998.

[19] L. Guillevin, A. Mahr, P. Callard et al., "Hepatitis B virusassociated polyarteritis nodosa: clinical characteristics, outcome, and impact of treatment in 115 patients," Medicine, vol. 84, no. 5, pp. 313-322, 2005.

[20] R. Bhimma, M. G. Hammond, H. M. Coovadia, M. Adhikari, and C. A. Connolly, "HLA class I and II in black children with hepatitis B virus-associated membranous nephropathy," Kidney International, vol. 61, no. 4, pp. 1510-1515, 2002.

[21] J. Cai, X. Fan, L. Mou et al., "Association of reduced renal function with hepatitis B virus infection and elevated alanine aminotransferase," Clinical Journal of the American Society of Nephrology, vol. 7, no. 10, pp. 1561-1566, 2012.

[22] J.-J. Lee, M.-Y. Lin, Y.-H. Yang, S.-N. Lu, H.-C. Chen, and S.J. Hwang, "Association of hepatitis $\mathrm{C}$ and $\mathrm{B}$ virus infection with CKD in an endemic area in Taiwan: a cross-sectional study," The American Journal of Kidney Diseases, vol. 56, no. 1, pp. 23-31, 2010.

[23] H. Izzedine, V. Launay-Vacher, and G. Deray, "Antiviral druginduced nephrotoxicity," The American Journal of Kidney Diseases, vol. 45, no. 5, pp. 804-817, 2005.

[24] H. Izzedine, V. Launay-Vacher, C. Isnard-Bagnis, and G. Deray, "Antiviral drug-induced kidney and electrolytes disorders," Minerva Urologica e Nefrologica, vol. 55, no. 3, pp. 157-172, 2003.

[25] R. J. Fontana, H.-W. L. Hann, R. P. Perrillo et al., "Determinants of early mortality in patients with decompensated chronic hepatitis B treated with antiviral therapy," Gastroenterology, vol. 123, no. 3, pp. 719-727, 2002.

[26] H. Izzedine, J. S. Hulot, V. Launay-Vacher et al., "Renal safety of adefovir dipivoxil in patients with chronic hepatitis B: two double-blind, randomized, placebo-controlled studies," Kidney International, vol. 66, no. 3, pp. 1153-1158, 2004.

[27] J.-F. Huang, W.-L. Chuang, C.-Y. Dai et al., "Viral hepatitis and proteinuria in an area endemic for hepatitis B and C infections: another chain of link?" Journal of Internal Medicine, vol. 260, no. 3, pp. 255-262, 2006.

[28] N. B. Ha, N. B. Ha, R. T. Garcia et al., "Renal dysfunction in chronic hepatitis B patients treated with adefovir dipivoxil," Hepatology, vol. 50, no. 3, pp. 727-734, 2009.

[29] C. Capeillère-Blandin, V. Gausson, A. T. Nguyen, B. DescampsLatscha, T. Drüeke, and V. Witko-Sarsat, "Respective role of uraemic toxins and myeloperoxidase in the uraemic state," Nephrology Dialysis Transplantation, vol. 21, no. 6, pp. 1555$1563,2006$.

[30] B. Descamps-Latscha, T. Drüeke, and V. Witko-Sarsat, "Dialysis-induced oxidative stress: biological aspects, clinical consequences, and therapy," Seminars in Dialysis, vol. 14, no. 3 , pp. 193-199, 2001.

[31] V. Witko-Sarsat, P. Rieu, B. Descamps-Latscha, P. Lesavre, and L. Halbwachs-Mecarelli, "Neutrophils: molecules, functions and pathophysiological aspects," Laboratory Investigation, vol. 80, no. 5, pp. 617-654, 2000.

[32] P. Wong, S. Mak, and A. K. Wong, "Management of chronic hepatitis $B$ infection in patients with end-stage renal disease and dialysis," Hepatitis B Annual, vol. 3, Article ID 76e105, 2006. 
[33] W. T. London, J. S. Drew, E. D. Lustbader, B. G. Werner, and B. S. Blumberg, "Host responses to hepatitis B infection in patients in a chronic hemodialysis unit," Kidney International, vol. 12, no. 1, pp. 51-58, 1977.

[34] P.-N. Wong, T.-T. Fung, A. N. H. Chan et al., "Unusual case of hepatitic cholestasis resembling fibrosing cholestatic hepatitis in a dialysis patient with chronic hepatitis B infection," Journal of Gastroenterology and Hepatology, vol. 21, no. 10, pp. 1635-1637, 2006.

[35] National Kidney Foundation, "K/DOQI clinical practice guidelines for chronic kidney disease: evaluation, classification, and stratification," American Journal of Kidney Diseases, vol. 39, no. 2, supplement 1, pp. S1-S266, 2002.

[36] A. S. Levey, K.-U. Eckardt, Y. Tsukamoto et al., "Definition and classification of chronic kidney disease: a position statement from Kidney Disease: improving Global Outcomes (KDIGO)," Kidney International, vol. 67, no. 6, pp. 2089-2100, 2005.

[37] C. Molino, F. Fabbian, M. Cozzolino, and C. Longhini, "The management of viral hepatitis in CKD patients: an unresolved problem," International Journal of Artificial Organs, vol. 31, no. 8, pp. 683-696, 2008.

[38] F. Fabrizi, P. Messa, and P. Martin, "Hepatitis B virus infection and the dialysis patient," Seminars in Dialysis, vol. 21, no. 5, pp. 440-446, 2008.

[39] J. H. Hoofnagle, "Reactivation of hepatitis B," Hepatology, vol. 49, supplement 5, pp. S156-S165, 2009.

[40] J. M. López-Alcorocho, G. Barril, N. Ortiz-Movilla et al., "Prevalence of hepatitis B, hepatitis C, GB virus C/hepatitis G and TT viruses in predialysis and hemodialysis patients," Journal of Medical Virology, vol. 63, no. 2, pp. 103-107, 2001.

[41] P. Marcellin, E. J. Heathcote, T. Berg et al., "Effects of tenofovir disoproxil fumarate on renal function in chronic HBV patients in three global randomized studies," in Annual Meeting of the European Association for the Study of the Liver, 2011, Poster.

[42] R. G. Gish, M. D. Clark, S. D. Kane, R. E. Shaw, M. F. Mangahas, and S. Baqai, "Similar risk of renal events among patients treated with tenofovir or entecavir for chronic hepatitis B," Clinical Gastroenterology and Hepatology, vol. 10, no. 8, pp. 941-946, 2012.

[43] S. Amet, J. P. Bronowicki, D. Thabut et al., "HARPE study: prevalence of renal abnormalities in chronic HBV infection," in Proceedings of the 63rd Annual Meeting of the American Association for the Study of Liver Diseases (AASLD '12), vol. 56, pp. 191A-1144A, Boston, Mass, USA, November 2012.

[44] S. J. Hadziyannis, N. C. Tassopoulos, E. J. Heathcote et al., "Adefovir dipivoxil for the treatment of hepatitis B e antigennegative chronic hepatitis B," The New England Journal of Medicine, vol. 348, no. 9, pp. 800-807, 2003.

[45] P. Marcellin, T.-T. Chang, S. G. Lim et al., "Adefovir dipivoxil for the treatment of hepatitis B e antigen-positive chronic hepatitis B," The New England Journal of Medicine, vol. 348, no. 9, pp. 808816, 2003.

[46] K. Deterding, N. Lampe, J. Reijnders et al., "Prevalence and severity of kidney dysfunction in patients with chronic hepatitis B in Europe: data from the European VIRGIL cohort," in Proceedings of the Annual Meeting of the European Association for the Study of the Liver, 2011.

[47] M. Tanaka, F. Suzuki, Y. Seko et al., "Renal dysfunction and hypophosphatemia during long-term lamivudine plus adefovir dipivoxil therapy in patients with chronic hepatitis B," Journal of Gastroenterology, vol. 49, no. 3, pp. 470-480, 2014.
[48] R. D. Cooper, N. Wiebe, N. Smith, P. Keiser, S. Naicker, and M. Tonelli, "Systematic review and meta-analysis: renal safety of tenofovir disoproxil fumarate in HIV-infected patients," Clinical Infectious Diseases, vol. 51, pp. 496-505, 2010.

[49] R. Scherzer, M. Estrella, Y. Li et al., "Association of tenofovir exposure with kidney disease risk in HIV infection," AIDS, vol. 26, no. 7, pp. 867-875, 2012.

[50] M. O. Monteagudo-Chu, M. H. Chang, H. B. Fung, and N. Bräu, "Renal toxicity of long-term therapy with tenofovir in HIVinfected patients," Journal of Pharmacy Practice, vol. 25, no. 5, pp. 552-559, 2012.

[51] P. Marcellin, E. J. Heathcote, M. Buti et al., "Tenofovir disoproxil fumarate versus adefovir dipivoxil for chronic hepatitis B," The New England Journal of Medicine, vol. 359, no. 23, pp. 24422455, 2008.

[52] E. J. Heathcote, P. Marcellin, M. Buti et al., "Three-year efficacy and safety of tenofovir disoproxil fumarate treatment for chronic hepatitis B," Gastroenterology, vol. 140, no. 1, pp. 132143, 2011.

[53] P. Marcellin, E. Gane, M. Buti et al., "Regression of cirrhosis during treatment with tenofovir disoproxil fumarate for chronic hepatitis B: a 5-year open-label follow-up study," The Lancet, vol. 381, no. 9865, pp. 468-475, 2013.

[54] V. Mallet, P. Sogni, A. Vallet-Pichart et al., Renal Impairment under Nucleos(t)ide Analogs in A Monocentric Cohort of Patients with Chronic HBV Monoinfection: The BeSafe Study, abstract 1444, American Association for the Study of Liver Disease (AASLD), 2011.

[55] D. M. Gracey, P. Snelling, P. McKenzie, and S. I. Strasser, "Tenofovir-associated Fanconi syndrome in patients with chronic hepatitis B monoinfection," Antiviral Therapy, vol. 18, no. 7, pp. 945-948, 2013.

[56] S. T. Law, K. K. Li, and Y. Y. Ho, "Acquired fanconi syndrome associated with prolonged adefovir dipivoxil therapy in a chronic hepatitis B patient," The American Journal of Therapeutics, vol. 20, pp. e713-e716, 2013.

[57] A. A. M. Morris, S. V. Baudouin, and M. H. Snow, "Renal tubular acidosis and hypophosphataemia after treatment with nucleoside reverse transcriptase inhibitors," AIDS, vol. 15, no. 1, pp. 140-141, 2001.

[58] C. M. Lange, J. Bojunga, W. P. Hofmann et al., "Severe lactic acidosis during treatment of chronic hepatitis B with entecavir in patients with impaired liver function," Hepatology, vol. 50, no. 6, pp. 2001-2006, 2009.

[59] X. Li, C. Zhong, S. Yang et al., "Influence of adefovir dipivoxil or telbivudine monotherapy on renal function of patients with chronic hepatitis B," Nan Fang Yi Ke Da Xue Xue Bao, vol. 32, no. 6, pp. 826-829, 2012.

[60] Y.-F. Liaw, E. Gane, N. Leung et al., "2-year GLOBE trial results: telbivudine is superior to lamivudine in patients with chronic hepatitis B," Gastroenterology, vol. 136, no. 2, pp. 486-495, 2009.

[61] Y. Wang, S. Thongsawat, E. J. Gane et al., "Efficacy and safety of continuous 4-year telbivudine treatment in patients with chronic hepatitis B," Journal of Viral Hepatitis, vol. 20, no. 4, pp. e37-e46, 2013.

[62] T. Piratvisuth, P. Komolmit, T. Tanwandee et al., "52-week efficacy and safety of telbivudine with conditional tenofovir intensification at week 24 in HBeAg-positive chronic hepatitis B," PLoS ONE, vol. 8, no. 2, Article ID e54279, 2013.

[63] G. R. Matzke, G. R. Aronoff, A. J. Atkinson et al., "Drug dosing consideration in patients with acute and chronic kidney diseasea clinical update from Kidney Disease: improving Global 
Outcomes (KDIGO)," Kidney International, vol. 80, no. 11, pp. 1122-1127, 2011.

[64] European Association for the Study of the Liver, "EASL clinical practice guidelines: management of chronic hepatitis B virus infection," Journal of Hepatology, vol. 57, no. 1, pp. 167-185, 2012.

[65] A. J. Atkinson Jr. and S.-M. Huang, "Nephropharmacology: drugs and the kidney," Clinical Pharmacology \& Therapeutics, vol. 86, no. 5, pp. 453-456, 2009.

[66] L. A. Stevens and A. S. Levey, "Use of the MDRD study equation to estimate kidney function for drug dosing," Clinical Pharmacology and Therapeutics, vol. 86, no. 5, pp. 465-467, 2009.

[67] SiteGPR, "The reference source of information for the safe use of drugs in patients with renal disease," http://www.sitegpr.com/. 


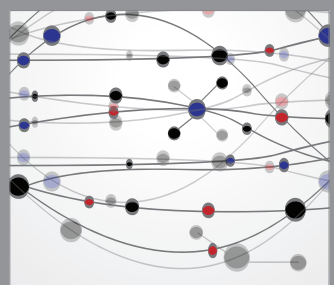

The Scientific World Journal
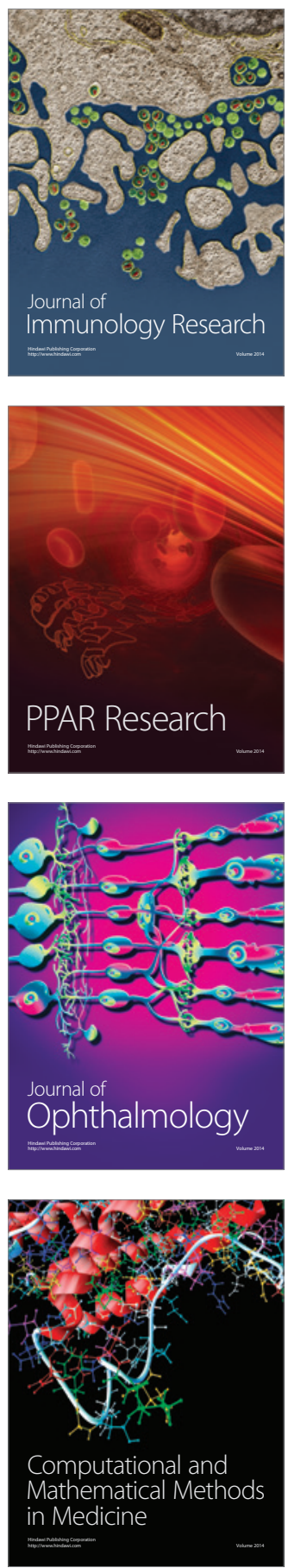

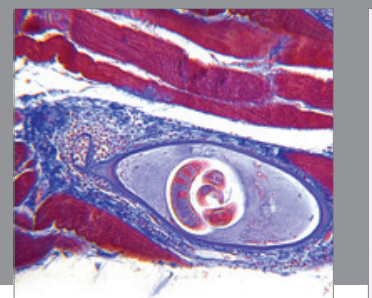

Gastroenterology

Research and Practice
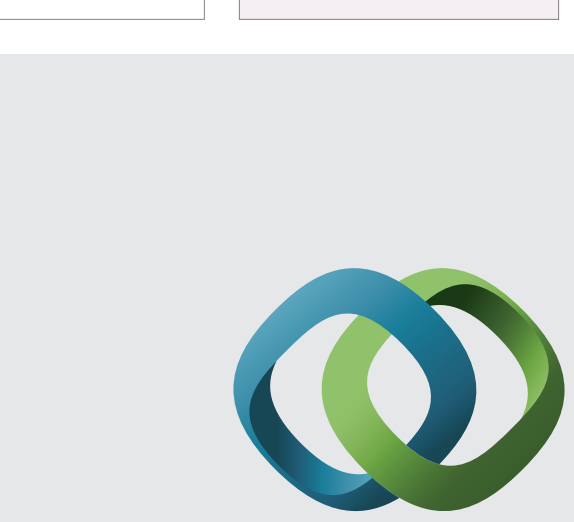

\section{Hindawi}

Submit your manuscripts at

http://www.hindawi.com
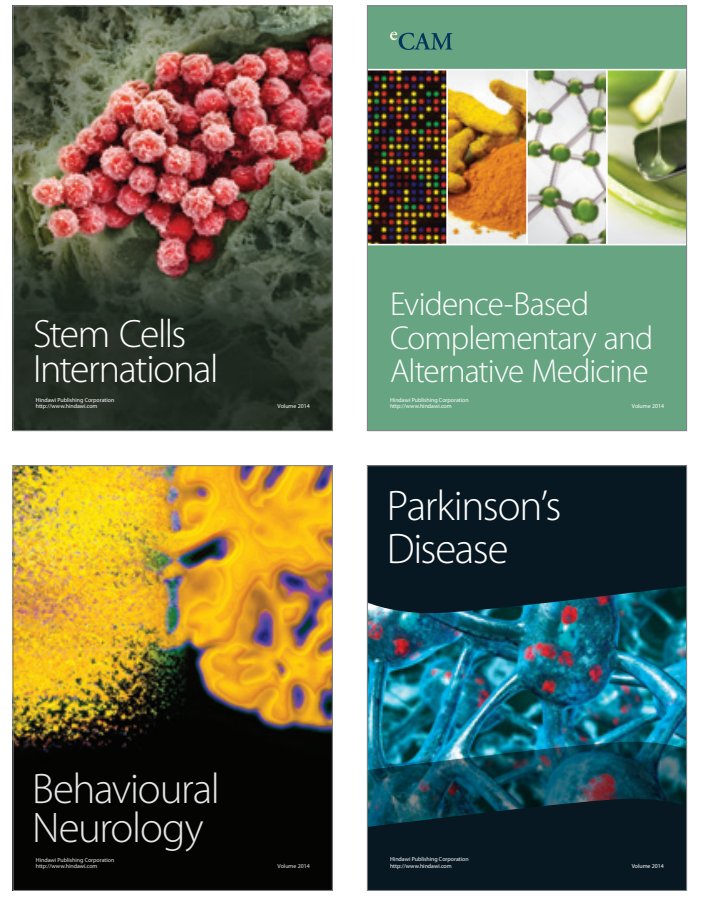
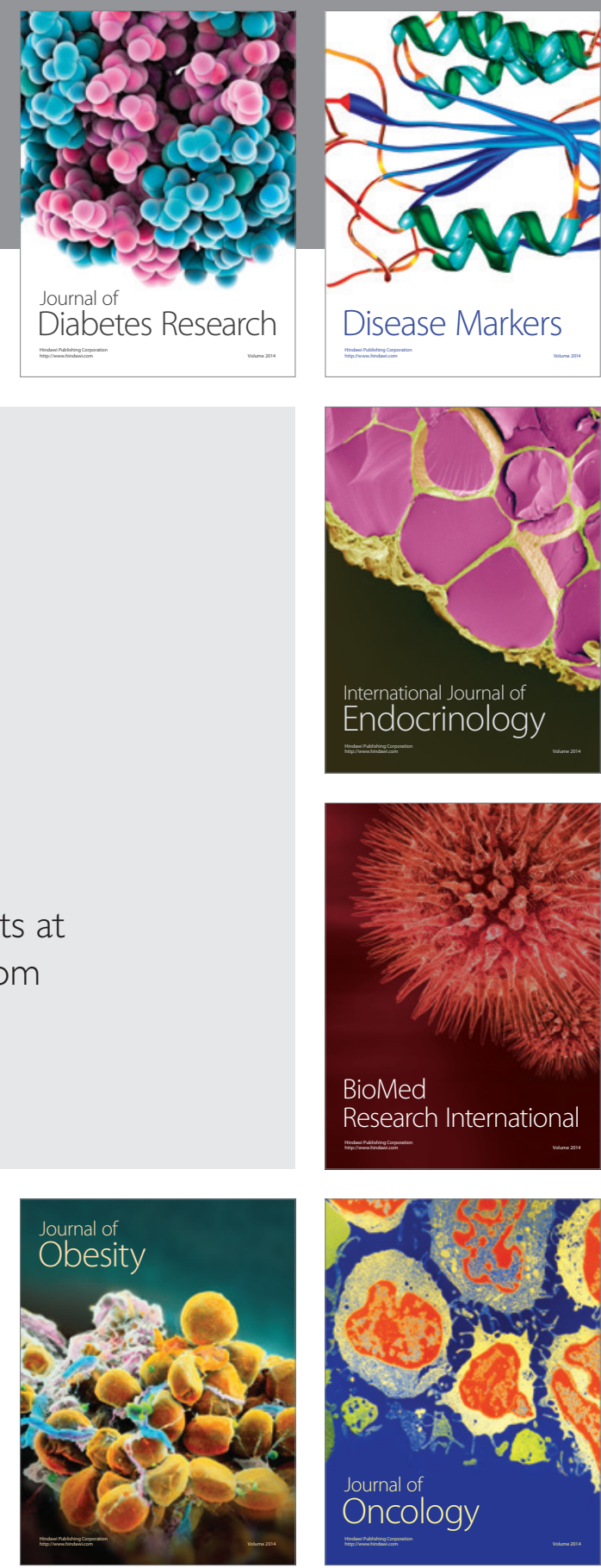

Disease Markers
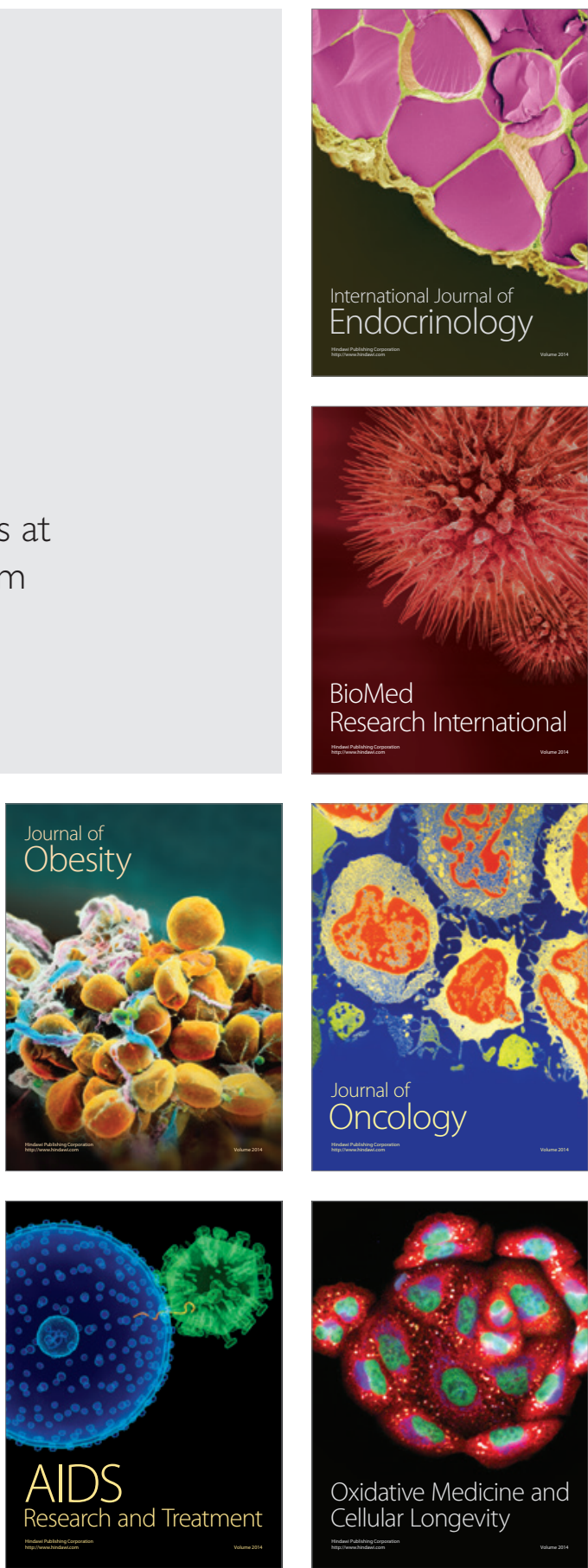